\title{
Genotyping of human papillomavirus DNA in Wielkopolska region
}

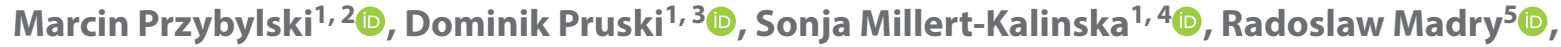 \\ Malgorzata Lagiedo-Zelazowska ${ }^{6}{ }^{\mathbb{D}}$, Jan Sikora ${ }^{6}$, Andrzej Zmaczynski ${ }^{7} \mathbb{D}$, Rafal Baran ${ }^{7}{ }^{\mathbb{D}}$, \\ Hanna Twardowska7 , Anna Horbaczewska7 ${ }^{7}$, Robert Jach ${ }^{7}$ (i) \\ ${ }^{1}$ Department of Obstetrics and Gynecology, District Public Hospital in Poznan, Poland \\ ${ }^{2}$ Marcin Przybylski M.D. Gynecology Specialised Practise, Poznan, Poland \\ ${ }^{3}$ Dominik Pruski M.D. Gynecology Specialised Medical Practice Poznan, Poland \\ ${ }^{4}$ Poznan University of Medical Sciences, Poland \\ ${ }^{5}$ Department of Oncology, Poznan University of Medical Sciences, Poznan, Poland \\ ${ }^{6}$ Department of Immunology, Chair of Patomorphology and Clinical Immunology, Poznan University of Medical Sciences, \\ Poznan, Poland \\ ${ }^{7}$ Department of Gynecology and Obstetrics, Jagiellonian University Collegium Medicum, Cracow, Poland
}

\begin{abstract}
Objectives: Human papillomavirus infection (HPV) is one of the most common sexually transmitted diseases. Long-term exposure to the HPV leads to development of high-grade squamous intraepithelial lesions that can eventually transform into cervical cancer.

The aim of the study was to assess the HPV genotype distribution in patients with abnormal pap smear and provide prospective study.

Material and methods: We obtained material from 674 women who registered to Specialist Medical Practice in the years 2008-2020. The sample for the molecular test was collected using combi brush and forwarded to the independent, standardized laboratory. HPV detection was done using PCR followed by DNA enzyme immunoassay and reverse hybridization line probe assay for virus genotyping. Sequence analysis was performed to characterize virus genotypes in HPV - positive samples.

Results: We found that $53 \%$ of patients tested positive for HPV. The percentage decreased with age. The following HPV types were the most common: HPV - 16 (24.5\%), HPV - 53 (13.1\%), HPV - 31 (10.3\%), HPV - 51 (9.7\%), HPV - 56 (9.5\%). Conclusions: Our results suggest that type-specific, high-risk HPV DNA - based screening should focus on HPV types $16,31,51,56$.
\end{abstract}

Key words: HPV; HPV genotypes; HPV screening; cervical cancer

Ginekologia Polska 2022; 93, 7: 546-551

\section{INTRODUCTION}

Cervical cancer $(\mathrm{Cc})$ remains the fourth most frequent cancer in women worldwide causing about 275,000 deaths annually $[1,2]$. There are many factors affecting the development of this life-threatening disease, such as the socio-economic status, the age of first sexual intercourse, alcohol consumption or smoking, as well as genetic load, immunosuppression and a large number of pregnancies and births (especially for young women) [3]. However, the most important factor in developing cervical cancer is pri- marily persistent infection with high-risk HPV (HR HPV). It can lead to an uncontrolled course of infection and is the direct cause of the vast majority of cervical intraepithelial neoplasia and invasive cervical cancers. The oncogenic potential of particular HPV genotypes has been acknowledged since the discovery of the definitive association of HPV as the indubitable etiological agent for development of SIL and cervical cancer. The role of human papillomavirus in cervical cancer was established over 40 years ago $[4,5]$.

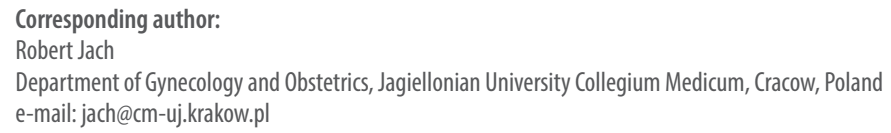


Genotypes 16 and 18 are assumed to be responsible for about $70 \%$ of cc cases $[6,7]$.

A growing number of countries are replacing Pap-smears with molecular HPV testing as the primary screening modality. Both the American Cancer Society (ACS) and the European Society for Medical Oncology (ESCO) recommend a new pattern of cervical cancer screening $[8,9]$. ACS recommends testing patients between 25 and 65 years of age every five years. Pap-smear has been the standard method for cervical cancer screening for over half of the century. It has reduced the incidence by $60-90 \%$ and the death rate by $90 \%$. However, the limitation of Pap-smear is sensitivity $(\sim 50 \%)$ and a significant proportion of inadequate specimens. A pooled analysis of four randomized controlled trials of HPV-based cervical screening versus Pap-smear showed $60-70 \%$ greater protection against invasive cancer in favor of HPV-test [10]. Thirteen HPV genotypes are recognized to be oncogenes with high-risk potential by the International Agency for Research on Cancer [11].

On a global scale, HPV infections cause more than half of infection-linked cancers among women and barely $5 \%$ in males. Vaccines against the high-risk HPV types 16 and 18 represent the first prophylactic vaccines developed directly to prevent a major human cancer (cc). A significant decrease in the incidence of cervical cancer has been observed over the past several decades due to preventive measures and screening.

\section{Objectives}

This paper summarizes the results of HPV DNA genotyping in the Wielkopolska region. So far, we do not have reliable data on the contribution of selected oncogenic HPV types in the formation of cervical pathology in the Polish population. Our aim is to provide distribution of particular HPV genotypes in specific age groups. This knowledge might enable estimating the potential effectiveness of HPV vaccines as primary prevention.

\section{MATERIAL AND METHODS}

This study included 674 patients who registered to Specialist Medical Practice in the years 2008-2020 for regular cervical screening. Parallel to the Pap-smear, the women were tested for the presence of HPV which genotypes were later determined. The sample for a molecular test (Linear Array HPV Genotyping-Roche Diagnostics) was collected from the external os of the cervix and vaginal wall with a use of combi brush. The obtained specimen was placed into a liquid-based medium Solution. An HPV test is a quality test that serves to identify high- risk HPV DNA of the following genotypes: $6,11,16,18,26,31,33$, $35,39,40,42,43,44,45,51,52,53,54,55,56,58,59,61$, $62,64,66,67,68,68 \mathrm{a}, 68 \mathrm{~b}, 69,70,71,72,73,81,82,83,84$,
87, CP6108, 90 in vitro. A positive result in molecular tests confirms the presence of DNA of at least one of the mentioned above oncogenic types of human papillomavirus in the collected specimens.

If needed, a following colposcopy and biopsy were performed. Specialist in gynecologic oncology with 10-year experience examined colposcopy with SmartOPTIC colposcope. Trial with a $5 \%$ aqueous solution of acetic acid as well as Schiller's test with Lugol's iodine were performed in all cases. The colposcopic images were evaluated according to Reid's Colposcopic Index which assesses the color, lesion boundaries and surface, blood vessels, and iodine test. All colposcopic images were archived. We used classification created by The International Federation of Cervical Pathology and Colposcopy and recommended by the Polish Society of Colposcopy and Cervical Pathophysiology.

Calculations were performed using the statistical package Statistica (ver. 13.3). Graphs were created with the help of Excel. Statistical hypotheses were verified at the level of significance of 0.05 . The Shapiro-Wilk test was used to assess whether the data distribution is normal and Spearman's rho coefficient was used in order to analyze its correlation. The correlation between individual genotypes and age groups was analyzed with a Chi-square test.

\section{RESULTS}

The mean age of the entire population was 34 . A total of 359 patients $(53.3 \%)$ tested positive for HPV DNA. The quantitative and percentage distribution of individual genotypes is presented in Table 1. Figure 1 shows the percentage distribution of HPV-positive women in each age group. The HPV genotype 16 and 53 were the most common amongst HPV-positive women. They accounted for $24.5 \%$ and $13.4 \%$, respectively. As far as both genotypes are concerned, the correlation between them and particular age groups was not found $(p>0.05)$. A detailed analysis is presented in Table 2 and 3.

The individual HPV genotypes have been allocated to three groups:

- Group A - carcinogenic to humans: 16, 18, 31, 33, 35, $39,45,51,52,56,58,59,64,67,68 a, 68 b, 73,82$;

- Group B - either probably or possibly carcinogenic to humans: 26, 53, 66, 69;

- Group C - unclassifiable as carcinogenic to humans: $6,11,40,42,44,54,55,61,62,70,71,72,81,83,84,87$, 90, CP6108.

Table 4 presents the basic descriptive statistics and the result of the normality distribution of the Shapiro-Wilk test (W). The result is statistically significant for all variables; therefore the distribution of the examined variables is highly deviating from normal $(p<0.001)$. The correlation of the 


\begin{tabular}{|c|c|c|c|c|}
\hline $\begin{array}{c}\text { HPV } \\
\text { genotype }\end{array}$ & $\begin{array}{c}\text { Presence } \\
\mathbf{n}\end{array}$ & $\begin{array}{c}\text { Presence } \\
\%\end{array}$ & $\begin{array}{c}\text { Deficiency } \\
n\end{array}$ & $\begin{array}{c}\text { Deficiency } \\
\%\end{array}$ \\
\hline 16 & 88 & 13.1 & 586 & 86.9 \\
\hline 53 & 48 & 7.1 & 626 & 92.9 \\
\hline 31 & 37 & 5.5 & 637 & 94.5 \\
\hline 51 & 35 & 5.2 & 639 & 94.8 \\
\hline 56 & 34 & 5.0 & 640 & 95.0 \\
\hline 54 & 32 & 4.7 & 642 & 95.3 \\
\hline 52 & 27 & 4.0 & 647 & 96.0 \\
\hline 59 & 27 & 4.0 & 647 & 96.0 \\
\hline 66 & 27 & 4.0 & 647 & 96.0 \\
\hline 18 & 26 & 3.9 & 648 & 96.1 \\
\hline 73 & 24 & 3.6 & 650 & 96.4 \\
\hline 6 & 23 & 3.4 & 651 & 96.6 \\
\hline 61 & 21 & 3.1 & 653 & 96.9 \\
\hline 42 & 20 & 3.0 & 654 & 97.0 \\
\hline 39 & 19 & 2.8 & 655 & 97.2 \\
\hline 45 & 19 & 2.8 & 655 & 97.2 \\
\hline 62 & 17 & 2.5 & 657 & 97.5 \\
\hline CР6108 & 15 & 2.2 & 659 & 97.8 \\
\hline 33 & 14 & 2.1 & 660 & 97.9 \\
\hline 84 & 14 & 2.1 & 660 & 97.9 \\
\hline 67 & 11 & 1.6 & 663 & 98.4 \\
\hline 68 & 11 & 1.6 & 663 & 98.4 \\
\hline 90 & 11 & 1.6 & 663 & 98.4 \\
\hline 35 & 10 & 1.5 & 664 & 98.5 \\
\hline 58 & 10 & 1.5 & 664 & 98.5 \\
\hline 82 & 8 & 1.2 & 666 & 98.8 \\
\hline 81 & 8 & 1.2 & 666 & 98.8 \\
\hline 83 & 7 & 1.0 & 667 & 99.0 \\
\hline 11 & 5 & 0.7 & 669 & 99.3 \\
\hline 40 & 5 & 0.7 & 669 & 99.3 \\
\hline 55 & 5 & 0.7 & 669 & 99.3 \\
\hline 70 & 5 & 0.7 & 669 & 99.3 \\
\hline 87 & 3 & 0.4 & 671 & 99.6 \\
\hline 44 & 2 & 0.3 & 672 & 99.7 \\
\hline $68 a$ & 1 & 0.1 & 673 & 99.9 \\
\hline $68 b$ & 1 & 0.1 & 673 & 99.9 \\
\hline 72 & 1 & 0.1 & 673 & 99.9 \\
\hline 64 & 0 & 0 & 674 & 100 \\
\hline 26 & 0 & 0 & 674 & 100 \\
\hline 69 & 0 & 0 & 674 & 100 \\
\hline 71 & 0 & 0 & 674 & 100 \\
\hline
\end{tabular}

$\mathrm{n}$ - number, HPV - human papillomavirus

occurrence of particular genotypes in specific age groups is statistically significant. This correlation is negative, so the frequency of occurrence of particular groups of HPV genotypes decreases with age (Fig. 1 and Tab. 4). The relationship calculated using Spearman's rho coefficient, however, is weak (Tab. 5).

For individual genotypes, the following relationships were found:

- genotype 51(carcinogenic): significantly more frequent in patients under 25 years of age in comparison to all other age groups $(p=0.001)$, significantly more frequent in group 25-30 in comparison to group 30-35 ( $p<0.001)$;

- genotype 56 (carcinogenic): significantly more frequent in groups $25-30$ and $30-35$ in comparison to group $40-45$ ( $p=0.005$ and $p=0.024$ respectively);

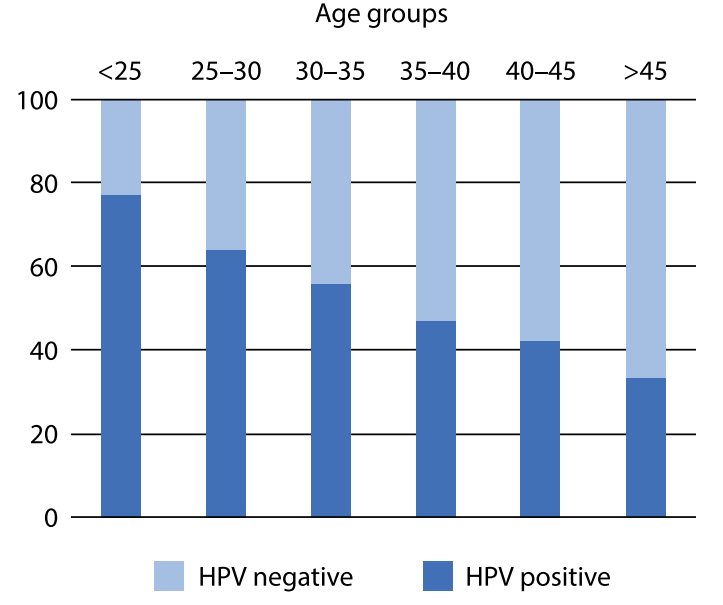

Figure 1. Distribution of HPV positive patients in specific age groups; HPV - human papillomavirus

- genotype 59 (carcinogenic): significantly more frequent in patients under 25 years of age in comparison to groups 30-35, 35-40 and over 45 years ( $p<0.001$, $p=0.0015$ and $p=0.009$, respectively) and statistically significantly more frequent in patients in group 25-30 in comparison to groups 30-35, 35-40 and over 45 years of age ( $p=0.006, p=0.015$ and $p=0.049$, respectively);

- genotype 67 (carcinogenic): significantly more frequent in patients in group 25-30 in comparison to groups 3035 and $35-40(p<0.001$ and $p=0.004$, respectively), significantly more frequent in group $25-30$ in comparison to groups 30-35 and 35-40 $(p=0.014$ and $p=0.037$, respectively) and significantly more frequent in group 30-35 in comparison to group over 45 years of age $(p=0.027)$;

- genotype 73 (carcinogenic): significantly more frequent in patients in group under 25 years of age in comparison to groups 30-35 and 40-45 ( $p=0.016$ and $p=0.008$, respectively) and significantly more frequent in group 25-30 in comparison to groups 30-35 and $40-45$ ( $p=0.01$ and $p=0.01$, respectively);

- genotype 66 (possibly carcinogenic): significantly more frequent in patients under 25 years of age in comparison to all other age groups ( $p=0.0035)$.

There were also some significant interactions between other genotypes, such as 6,52, 54 but because of their non-carcinogenic character, these were not mentioned.

In case of a positive HPV result, abnormal Pap-smear or a clinically suspicious cervix image, colposcopy with biopsy was performed. As a result, a biopsy was examined in 321 patients. In over half of the cases no pathology was found (NILM was diagnosed in $50 \%$ of patients). LSIL was present in 87 (27\%) whereas HSIL in 71 (22\%) samples. No squamous cervical cancer was histologically confirmed. However, what is noteworthy, two cases of adenocarcinomas were detected. 


\begin{tabular}{|c|c|c|c|c|c|c|c|c|c|}
\hline Genotype 16 & $\begin{array}{c}\text { Group } \\
<25\end{array}$ & $\begin{array}{l}\text { Group } \\
25-30\end{array}$ & $\begin{array}{l}\text { Group } \\
30-35\end{array}$ & $\begin{array}{l}\text { Group } \\
35-40\end{array}$ & $\begin{array}{l}\text { Group } \\
40-45\end{array}$ & $\begin{array}{c}\text { Group } \\
>45\end{array}$ & $\begin{array}{l}\text { Line } \\
\text { all }\end{array}$ & $\mathbf{X} 2$ & $\mathbf{p}$ \\
\hline Deficiency & 43 & 129 & 156 & 120 & 70 & 68 & 586 & & \\
\hline $\begin{array}{l}\% \text { Column } \\
\% \text { Line } \\
\% \text { All }\end{array}$ & $\begin{array}{c}89.58 \\
7.34 \\
6.38\end{array}$ & $\begin{array}{l}83.23 \\
22.01 \\
19.14\end{array}$ & $\begin{array}{l}85.25 \\
26.62 \\
23.15\end{array}$ & $\begin{array}{l}90.91 \\
20.48 \\
17.80\end{array}$ & $\begin{array}{l}86.42 \\
11.95 \\
10.39\end{array}$ & $\begin{array}{l}90.67 \\
11.60 \\
10.09\end{array}$ & 86.94 & & \\
\hline Presence & 5 & 26 & 27 & 12 & 11 & 7 & 88 & & \\
\hline $\begin{array}{l}\% \text { Column } \\
\% \text { Line } \\
\% \text { All }\end{array}$ & $\begin{array}{c}10.42 \\
5.68 \\
0.74\end{array}$ & $\begin{array}{c}16.77 \\
29.55 \\
3.86\end{array}$ & $\begin{array}{c}14.75 \\
30.68 \\
4.01\end{array}$ & $\begin{array}{c}9.09 \\
13.64 \\
1.78\end{array}$ & $\begin{array}{c}13.58 \\
12.50 \\
1.63\end{array}$ & $\begin{array}{l}9.33 \\
7.93 \\
1.04\end{array}$ & 13.06 & 5.41 & 0.368 \\
\hline All & 48 & 155 & 183 & 132 & 81 & 75 & 674 & & \\
\hline$\%$ All & 7.12 & 23.00 & 27.15 & 19.58 & 12.02 & 11.13 & 100 & & \\
\hline
\end{tabular}

HPV - human papillomavirus; $\mathrm{p}-\mathrm{p}$ value

Table 3. Correlation between studied age groups and the presence of HPV genotype 53

\begin{tabular}{|c|c|c|c|c|c|c|c|c|c|}
\hline Genotype 53 & $\begin{array}{c}\text { Group } \\
<25\end{array}$ & $\begin{array}{l}\text { Group } \\
25-30\end{array}$ & $\begin{array}{l}\text { Group } \\
30-35\end{array}$ & $\begin{array}{l}\text { Group } \\
35-40\end{array}$ & $\begin{array}{l}\text { Group } \\
40-45\end{array}$ & $\begin{array}{l}\text { Group } \\
>45\end{array}$ & $\begin{array}{l}\text { Line } \\
\text { all }\end{array}$ & $\mathbf{X} 2$ & $\mathbf{p}$ \\
\hline $\begin{array}{l}\text { Deficiency } \\
\% \text { Column } \\
\% \text { Line } \\
\% \text { All }\end{array}$ & $\begin{array}{c}42 \\
87.50 \\
6.71 \\
6.23\end{array}$ & $\begin{array}{c}142 \\
91.61 \\
22.68 \\
21.07\end{array}$ & $\begin{array}{c}171 \\
93.44 \\
27.32 \\
25.37\end{array}$ & $\begin{array}{c}122 \\
92.42 \\
19.49 \\
18.10\end{array}$ & $\begin{array}{c}77 \\
95.06 \\
12.30 \\
11.42\end{array}$ & $\begin{array}{c}72 \\
96.00 \\
11.50 \\
10.68\end{array}$ & $\begin{array}{r}626 \\
92.88\end{array}$ & & \\
\hline $\begin{array}{l}\text { Presence } \\
\% \text { Column } \\
\% \text { Line } \\
\% \text { All }\end{array}$ & $\begin{array}{c}6 \\
12.50 \\
12.50 \\
0.89\end{array}$ & $\begin{array}{c}13 \\
8.39 \\
27.08 \\
1.93\end{array}$ & $\begin{array}{c}12 \\
6.56 \\
25.00 \\
1.78\end{array}$ & $\begin{array}{c}10 \\
7.58 \\
20.83 \\
1.48\end{array}$ & $\begin{array}{c}4 \\
4.94 \\
8.33 \\
0.59\end{array}$ & $\begin{array}{c}3 \\
4.00 \\
6.25 \\
0.45\end{array}$ & $\begin{array}{r}48 \\
7.12\end{array}$ & 4.29 & 0.508 \\
\hline $\begin{array}{l}\text { All } \\
\% \text { All }\end{array}$ & $\begin{array}{c}48 \\
7.12\end{array}$ & $\begin{array}{c}155 \\
23.00\end{array}$ & $\begin{array}{c}183 \\
27.15\end{array}$ & $\begin{array}{c}132 \\
19.58\end{array}$ & $\begin{array}{c}81 \\
12.02\end{array}$ & $\begin{array}{c}75 \\
11.13\end{array}$ & $\begin{array}{l}674 \\
100\end{array}$ & & \\
\hline
\end{tabular}

$\mathrm{HPV}$ - human papillomavirus; $\mathrm{p}-\mathrm{p}$ value

\begin{tabular}{|c|c|c|c|c|c|c|c|c|}
\hline HPV type & M & SD & LMod. & Min. & Max. & Skew. & $\mathbf{W}$ & $p$ \\
\hline Group A & 0.60 & 0.84 & 394 & 0 & 5 & 1.53 & 0.713 & $p<0.001$ \\
\hline Group B & 0.11 & 0.35 & 606 & 0 & 2 & 3.20 & 0.348 & $p<0.001$ \\
\hline Group C & 0.29 & 0.63 & 529 & 0 & 4 & 2.70 & 0.511 & $p<0.001$ \\
\hline
\end{tabular}

$\mathrm{HPV}$ - human papillomavirus; $\mathrm{M}$ - mean; $\mathrm{SD}$ - standard deviation; $\mathrm{p}-\mathrm{p}$ value

\section{DISCUSSION}

This study provides comprehensive information on the HPV prevalence and genotype distribution among a cohort of Polish women who were referred to a single center for HPV genotyping following either a diagnosis of abnormal cytology or for screening. We have not found such a database of one roof patients.

In comparison to another recent study conducted in Poland, we have noticed some discrepancies. As expected, the most frequent HPV genotype was 16 . It was present in $26 \%$ of all HPV-positive patients compared to $20 \%$ in mentioned study. On the other hand, negative patients constituted $46.7 \%$, and in the cited study $32.1 \%$. According to Smolarz et al. HPV genotype 18 was found in about
$14 \%$ of women, while in our observation, it was in 10th place and occurred twice less often (7.2\%) [12]. Contrary to the literature, we did not observe genotype 18 occurring frequently. That, however, could the result of our focus on a heterogeneous group, where neither SIL nor cervical cancer was the criterion. In line with previous studies, HPV 16, 31 , and 45 genotypes were most often detected in patients diagnosed with ASC-US or LSIL, whereas in patients with HSIL, genotypes $16,33,18,31,56$ were the most common $[13,14]$. We also provide data for the HPV types that are phylogenetically classified as oncogenic, such as HPV types $26,67,69$, and 82 , but seldomly described in epidemiological studies [15]. Little is known about the exact mechanism of HPV-associated carcinogenesis of these rare types due 
Table 5. Correlation between age groups and HPV genotypes divided into three groups

\begin{tabular}{|l|c|c|}
\hline & rho Spearman & p \\
\hline Age group \& Group A & -0.23 & 0.000 \\
\hline Age group \& Group B & -0.08 & 0.033 \\
\hline Age group \& Group C & -0.17 & 0.000 \\
\hline
\end{tabular}

HPV - human papillomavirus; $\mathrm{p}-\mathrm{p}$ value

to insufficient epidemiological evidences. The biological properties of the rare high-risk HPV types have only been investigated in a few studies, which included mostly cervical intraepithelial neoplasms lesions and a few cases of invasive cervical cancer [16].

As far as prevention is concerned, it is both important to detect lesions in the early stage and to identify risk-factors of carcinogenesis. Early diagnosed HPV-positive patients will be eligible for a high risk of cancer development. As a consequence, they will be subjected to tighter inspection and follow-up visits. The prevalence of HPV infection among women with subclinical or latent disease leads to different results. It depends on the studied population and used method of HPV detection. The highest percentage of infections is diagnosed using a PCR method which is recognized to have the highest sensitivity among all molecular biology techniques. It allows to detect the presence of one copy of HPV in 105-106 cells. PCR is now becoming a common diagnostic technique that is used in numerous laboratories. The results obtained from PCR are comparable and allow to avoid their false interpretation. The introduction of DNA testing has increased the effectiveness of screening programs in women over 30 years of age with the NILM (negative for intraepithelial lesion or malignancy) and reduced the number of unnecessary colposcopies and treatment in younger patients [17-20].

What is noticeable, the correlation of the appearance of particular genotypes in specific age groups is statistically significant - the frequency of occurrence of particular groups of HPV genotypes decreases with age. Over the past four to five decades the assessment of the distribution of HPV types in cervical cancer has been crucial for determining the cause of age-related differences. If the reason is the cohort effect, that could allow us to predict changes in the distribution of HPV types in the upcoming years, resulting in improvement of implementing preventive HPV-vaccination.

Originally, risk stratification in cervical screening based on the underlying HPV genotype was suggested in 2003 when the primary clinical HPV assays for screening indicated the detection of high-risk HPV genotype was performed either in a research setting or as an in-house test. Clifford et al. [21], suggested that HPV genotypes 16, 18, and 45 would merit closer surveillance than infection with other high-risk HPV genotypes. Subsequently, large-scale studies of cervical cancers displayed the contribution of different HPV genotypes to squamous cell carcinoma and adenocarcinoma. It served as a foundation to determine the hierarchy of high-risk HPV genotypes [22]. Throughout the next decade, studies showed that genotypes 31, 33, 52, and 58 confer risks similar to HPV 18 and 45, thereby establishing impetus for contemplating more complex screening algorithms using genotype-specific risk stratification. That resulted in forming more precise colposcopy referral recommendations and allowed to reduce [23-26] overtreatment. Thus, today's application of HPV diagnostics in screening distinguishes between a partial genotyping result for reporting of HPV 16 and 18, with the remaining high-risk HPV genotypes as a pooled result. A recent expert review by Xu et al., [27] assessing the accuracy of HPV 16/18 genotyping to triage LSIL cytology, points out that although the partial genotyping strategy increases the positive predictive value, the specificity declines compared with cytology. A more complete differentiation between genotypes may improve this strategy.

This work provides estimates of the important contribution of HPV types $16,31,51,56,52,59$, and 18 . These types might be considered while developing new vaccines with a wider efficacy range. The early detection of cancers associated with HPV types 16,31 , and 51 could be considered in screening programs aimed at clinical management based on the HPV genotype. Our results indicate which HPV types should be emphasized on when the cross-protective effects of current vaccines are assessed. What is more, they could come as applicable while preparing recommendations for HPV vaccines usage. According to our findings those type-specific, high-risk, HPV-DNA-based screening tests and protocols should be focused on HPV types 16,18 , $31,51,52,56$, and 59 .

\section{CONCLUSIONS}

Cervical cancer screening is recommended by clinical practice guidelines for being effective cancer preventive method. HPV 16 and 18 partial genotyping is implemented in several clinical screening guidelines. Evidence, that have been accumulated for over a decade, suggests that the definition should be expanded to include risk stratification on the full spectrum of high-risk HPV genotypes of women undergoing screening.

In the future, follow-up and vaccination status of patients may indicate a trend related to the extinction of some HPV genotypes in the vaccinated population. The advantage of our research is the long duration of the study. Close follow-up should last two years as up to $25 \%$ of relapses are observed within that period of time. During follow-up, both LSIL and HSIL were detected in 158 patients. It is a proof of 
necessity of supervision over the patients. Two cases of adenocarcinoma furtherly confirm that statement. That is why it is essential to build trust in the doctor-patient relationship, conduct social campaigns reminding about regular checkups and expand diagnostics beyond the exclusive cytology.

\section{Funding}

This research received no external funding.

\section{Conflicts of interest}

The authors declare no conflict of interest.

\section{REFERENCES}

1. Dijkstra MG, Snijders PJF, Arbyn M, et al. Cervical cancer screening: on the way to a shift from cytology to full molecular screening. Ann Oncol. 2014; 25(5): 927-935, doi: 10.1093/annonc/mdt538, indexed in Pubmed: 24445150.

2. Reels J, Jones $\mathrm{D}$, Chen $\mathrm{H}$, et al. Interventions to improve the uptake of cervical cancer screening among lower socioeconomic groups: A systematic review. Prev Med. 2018; 111:323-335, doi: 10.1016/j.ypmed.2017.11.019, indexed in Pubmed: 29203349.

3. Stefanek A, Durka P. Women's knowledge of prevention of cervical cancer. Pol Prz Nauk Zdr. 2014; 38: 1.

4. zur Ha. Similarities of papillomavirus infections with tumor promoters. Princess Takamatsu Symp. 1983; 14: 147-52, indexed in Pubmed: 6097579.

5. zur Hausen H. Papillomaviruses in the causation of human cancers a brief historical account. Virology. 2009; 384(2): 260-265, doi: 10.1016/j. virol.2008.11.046, indexed in Pubmed: 19135222.

6. Wilkinson DE, Baylis SA, Padley D, et al. Collaborative Study Group. Establishment of the 1st World Health Organization international standards for human papillomavirus type 16 DNA and type 18 DNA. Int J Cancer. 2010; 126(12): 2969-2983, doi: 10.1002/ijc.25039, indexed in Pubmed: 19904756.

7. Smith JS, Lindsay L, Hoots B, et al. Human papillomavirus type distribution in invasive cervical cancer and high-grade cervical lesions: a meta-analysis update. Int J Cancer. 2007; 121(3): 621-632, doi: 10.1002/ijc.22527, indexed in Pubmed: 17405118.

8. Marth C, Landoni F, Mahner S, et al. ESMO Guidelines Committee. Cervical cancer: ESMO Clinical Practice Guidelines for diagnosis, treatment and follow-up. Ann Oncol. 2017; 28(suppl_4): iv72-iv83, doi: 10.1093/annonc/mdx220, indexed in Pubmed: 28881916.

9. Fontham $\mathrm{E}$, Wolf $\mathrm{A}$, Church $\mathrm{T}$, et al. Cervical cancer screening for individuals at average risk: 2020 guideline update from the American Cancer Society. CA: A Cancer Journal for Clinicians. 2020; 70(5): 321-346, doi: 10.3322/caac. 21628

10. IARC Working Group on the Evaluation of Carcinogenic Risks to Humans. Biological agents. Volume 100 B. A review of human carcinogens. IARC Monogr Eval Carcinog Risks Hum. 2012; 100: 1-441, indexed in Pubmed: 23189750.

11. International Agency for Research on Cancer (IARC). The Grants Register 2018. IARC Monogr Eval Carcinog Risks Hum. 2018: 412-413, doi: 10.1007/978-1-349-94186-5_629.

12. Smolarz B, Samulak D, Szyłło K, et al. Cobas 4800 HPV detection in cervical samples of Polish women. Contemp Oncol (Pozn). 2019; 23(2): 92-95, doi: 10.5114/wo.2019.85880, indexed in Pubmed: 31316291.

13. Bedziński M, Józefiak A, Szczepańska M, et al. [The correlation of a positive DNA HPV HR test and genotyping human papilloma viruses with the presence of CIN, in women with cytologic evidence of ASC-US and LSIL]. Ginekol Pol. 2008; 79(7): 490-493, indexed in Pubmed: 18819456.

14. Kedzia W, Pruski D, Józefiak A, et al. [Genotyping of oncogenic human papilloma viruses in women with HG SIL diagnosis]. Ginekol Pol. 2010; 81(10): 740-744, indexed in Pubmed: 21117301.

15. Schiffman M, Clifford G, Buonaguro FM. Classification of weakly carcinogenic human papillomavirus types: addressing the limits of epidemiology at the borderline. Infect Agent Cancer. 2009; 4: 8, doi: 10.1186/1750-9378-4-8, indexed in Pubmed: 19486508.

16. Tsuda H, Hashiguchi $Y$, Nishimura $S$, et al. Relationship between HPV typing and abnormality of $\mathrm{G} 1$ cell cycle regulators in cervical neoplasm. Gynecol Oncol. 2003; 91(3): 476-485, doi: 10.1016/j.ygyno.2003.08.019, indexed in Pubmed: 14675665.

17. Stoler MH, Castle PE, Solomon D, et al. American Society for Colposcopy and Cervical Pathology. The expanded use of HPV testing in gynecologic practice per ASCCP-guided management requires the use of well-validated assays. Am J Clin Pathol. 2007; 127(3): 335-337, doi: 10.1309/RNF3C01JKADQCLKP, indexed in Pubmed: 17276947.

18. Giorgi-Rossi P, Carozzi F. New Technologies for Cervical Cancer screening (NTCC) Working Group. Efficacy of hu- man papillomavirus testing for the detection of invasive cervical cancers and cervical intraepithelial neoplasia: a randomized con- trolled trial. Lancet Oncol. 2010; 11: 249-257.

19. Raab SS. American Cancer Society, American Society for Colposcopy and Cervical Pathology, and American Society for Clinical Pathology Screening Guidelines for the Prevention and Early Detection of Cervical Cancer. Yearbook of Pathology and Laboratory Medicine. 2013; 2013: 273-275, doi: 10.1016/j.ypat.2012.11.013.

20. Stoler $\mathrm{MH}$, Wright TC, Sharma A, et al. ATHENA (Addressing THE Need for Advanced HPV Diagnostics) Study Group. The interplay of age stratification and HPV testing on the predictive value of ASC-US cytology. Results from the ATHENA HPV study. Am J Clin Pathol. 2012; 137(2): 295-303, doi: 10.1309/AJCPGW1V2BBWMOCX, indexed in Pubmed: 22261457.

21. Clifford GM, Smith JS, AguadoT, et al. Comparison of HPV type distribution in high-grade cervical lesions and cervical cancer: a meta-analysis. Br J Cancer. 2003; 89(1): 101-105, doi: 10.1038/sj.bjc.6601024, indexed in Pubmed: 12838308.

22. de Sanjose S, Quint WGv, Alemany L, et al. Retrospective International Survey and HPV Time Trends Study Group. Human papillomavirus genotype attribution in invasive cervical cancer: a retrospective cross-sectional worldwide study. Lancet Oncol. 2010; 11(11): 1048-1056, doi: 10.1016/S1470-2045(10)70230-8, indexed in Pubmed: 20952254.

23. Cuzick J, Ho L, Terry G, et al. Individual detection of 14 high risk human papilloma virus genotypes by the PapType test for the prediction of high grade cervical lesions. J Clin Virol. 2014;60(1):44-49, doi: 10.1016/j. jcv.2014.02.002, indexed in Pubmed: 24630483.

24. Franceschi S, Clifford GM. Re: A study of the impact of adding HPV types to cervical cancer screening and triage tests. J Natl Cancer Inst. 2005; 97(12): 938-939, doi: 10.1093/jnci/dji159, indexed in Pubmed: 15956659.

25. Nakamura Y, Matsumoto K, Satoh T, et al. HPV genotyping for triage of women with abnormal cervical cancer screening results: a multicenter prospective study. Int J Clin Oncol. 2015; 20(5): 974-981, doi: 10.1007/s10147-015-0789-4, indexed in Pubmed: 25652908.

26. Xi LFu, Schiffman M, Koutsky LA, et al. Lineages of oncogenic human papillomavirus types other than type 16 and 18 and risk for cervical intraepithelial neoplasia. J Natl Cancer Inst. 2014; 106(10), doi: 10.1093/jnci/dju270, indexed in Pubmed: 25217779.

27. Xu L, Benoy I, Cuschieri K, et al. Accuracy of genotyping for HPV16 and 18 to triage women with low-grade squamous intraepithelial lesions: a pooled analysis of VALGENT studies. Expert Rev Mol Diagn. 2019; 19(6): 543-551, doi: 10.1080/14737159.2019.1613890, indexed in Pubmed: 31035813. 